\title{
BMJ
}

\section{High risk clinical characteristics for subarachnoid haemorrhage in patients with acute headache: prospective cohort study}

\author{
Jeffrey J Perry, associate professor, ${ }^{1}$ lan G Stiell, professor and chair, ${ }^{1}$ Marco L A Sivilotti, associate professor, ${ }^{2}$ \\ Michael I Bullard, professor, ${ }^{3}$ Jacques S Lee, assistant professor, ${ }^{4}$ Mary Eisenhauer, associate professor of \\ medicine, ${ }^{5}$ Cheryl Symington, research coordinator, ${ }^{1}$ Melodie Mortensen, research coordinator, ${ }^{1}$ Jane \\ Sutherland, research coordinator, ${ }^{6}$ Howard Lesiuk, consulting neurosurgeon, ${ }^{7}$ George A Wells, professor \\ biostatistics and epidemiology ${ }^{8}$
}

${ }^{1}$ Department of Emergency

Medicine, University of Ottawa and Ottawa Hospital Research Institute, Ottawa, Ontario, Canada K1Y 4E9 ${ }^{2}$ Department of Pharmacology and Toxicology, Queen's University, Kingston, Ontario

${ }^{3}$ Division of Emergency Medicine, University of Alberta, Edmonton, Alberta

${ }^{4}$ Division of Emergency Medicine, University of Toronto, Toronto, Ontario

${ }^{5}$ Division of Emergency Medicine, University of Western Ontario,

London, Ontario

${ }^{6}$ University of Ottawa, Clinical Epidemiology Program, Ottawa Hospital Research Institute,

Ottawa, Ontario

${ }^{7}$ Division of Neurosurgery, Ottawa Hospital Research Institute, Ottawa, Ontario

${ }^{8}$ Department of Epidemiology and Community Medicine, Ottawa Hospital Research Institute,

Ottawa, Ontario

Correspondence to: J Perry jperry@ohrica

Cite this as: BMJ 2010;341:C5204 doi:10.1136/bmj.c5204

\section{ABSTRACT}

Objective To identify high risk clinical characteristics for subarachnoid haemorrhage in neurologically intact patients with headache.

Design Multicentre prospective cohort study over five years.

Setting Six university affiliated tertiary care teaching hospitals in Canada. Data collected from November 2000 until November 2005.

Participants Neurologically intact adults with a nontraumatic headache peaking within an hour.

Main outcome measures Subarachnoid haemorrhage, as defined by any of subarachnoid haemorrhage on computed tomography of the head, xanthochromia in the cerebrospinal fluid, or red blood cells in the final sample of cerebrospinal fluid with positive results on angiography. Physicians completed data collection forms before investigations.

Results In the 1999 patients enrolled there were 130 cases of subarachnoid haemorrhage. Mean (range) age was 43.4 (16-93), 1207 (60.4\%) were women, and 1546 $(78.5 \%)$ reported that it was the worst headache of their life. Thirteen of the variables collected on history and three on examination were reliable and associated with subarachnoid haemorrhage. We used recursive partitioning with different combinations of these variables to create three clinical decisions rules. All had $100 \%$ (95\% confidence interval $97.1 \%$ to $100.0 \%$ ) sensitivity with specificities from $28.4 \%$ to $38.8 \%$. Use of any one of these rules would have lowered rates of investigation (computed tomography, lumbar puncture, or both) from the current $82.9 \%$ to between $63.7 \%$ and $73.5 \%$.

Conclusion Clinical characteristics can be predictive for subarachnoid haemorrhage. Practical and sensitive clinical decision rules can be used in patients with a headache peaking within an hour. Further study of these proposed decision rules, including prospective validation, could allow clinicians to be more selective and accurate when investigating patients with headache.

\section{INTRODUCTION}

Headache is a common presenting complaint in emergency departments, accounting for about $2 \%$ of all visits. ${ }^{12}$ Although subarachnoid haemorrhage accounts for only $1-3 \%$ of these headaches, ${ }^{2-4}$ emergency physicians need to rule out this important diagnosis. Typically, these headaches have a sudden onset and are severe. ${ }^{5}$ Neurological deficits, including coma at presentation, make the decision to investigate some patients relatively straightforward. It is particularly important, however, to investigate alert neurologically intact patients who present with headache alone and who account for up to half of all patients with subarachnoid haemorrhage because they benefit most from prompt diagnosis. ${ }^{6}$ Misdiagnosis occurs in a small number of patients with subarachnoid haemorrhage on the initial visit, when appropriate investigations are not performed..$^{7-9}$ Missing a subarachnoid haemorrhage in an otherwise alert patient can lead to catastrophic morbidity or death. ${ }^{510-14}$ Prognosis is most favourable when patients are treated early, while they are clinically well (that is, alert with no neurological deficits), and untreated patients can have abrupt clinical worsening because of re-bleeding. ${ }^{15}$ Such patients epitomise the challenges of emergency medicine; the condition is uncommon and difficult to diagnose and yet they have the most to lose by a missed diagnosis. ${ }^{12} 141617$

Patients with suspected subarachnoid haemorrhage are typically investigated with unenhanced computed tomography and a lumbar puncture if the scan result is negative. Not surprisingly, current use of these investigations in alert patients with non-traumatic headache is inefficient. ${ }^{3}$ Computed tomography is a high volume imaging technology, which adds considerably to healthcare costs and involves radiation that can increase the risk of cancer. ${ }^{18}$ Over $95 \%$ of scans to rule out subarachnoid haemorrhage, however, yield negative results, and traditionally all of these patients then undergo lumbar puncture. ${ }^{311-13}$ Lumbar puncture can be painful and can result in a headache that might 
be worse than the original headache. ${ }^{19}$ Although it would be ideal to investigate only high risk patients, no previous research has safely and rigorously identified this high risk population.

We prospectively assessed clinical characteristics of neurologically intact patients in emergency departments with a headache peaking within an hour to determine which variables are predictive for subarachnoid haemorrhage and are reliable between physicians. We also combined these high risk variables into preliminary potential clinical decision rules. Such rules should be highly sensitive and reliable while also reducing the number of patients requiring investigation to rule out subarachnoid haemorrhage.

\section{METHODS}

Study design

This was a prospective multicentre cohort study conducted at six university affiliated tertiary care teaching hospitals in Canada. Data were collected from November 2000 to November 2005.

\section{Study population}

We included alert patients aged $\geq 16$ who presented to an emergency department with a chief complaint of non-traumatic headache peaking within an hour or of syncope associated with a headache. Alert was defined as a score of 15 on the Glasgow coma scale. Non-traumatic was defined as the absence of falls or direct trauma to the head in the previous seven days. Acute was defined as an interval of less than one hour from headache onset to peak intensity, and an interval of less than 14 days from headache onset to presentation.

We excluded patients with a history of three or more recurrent headaches of the same character and intensity as the presenting headache over a period of over six months; referred from other centres with a confirmed subarachnoid haemorrhage by either computed tomography or lumbar puncture; returned for reassessment of the same headache if they had already been investigated with computed tomography or lumbar puncture, or both; with papilloedema (as determined by treating physician); new focal neurological deficits, previous diagnosis of cerebral aneurysm or subarachnoid haemorrhage; previous diagnosis of a brain neoplasm; or known hydrocephalus.

\section{Data collection}

Attending emergency physicians or supervised residents in an emergency medicine training programme with input from their attending physician assessed all patients. Physicians were familiarised with the study and the standardised assessment by means of a formal one hour teaching presentation. Emergency physicians completed data forms to identify the presence or absence of 33 clinical findings in consecutive eligible patients. When feasible, we requested that the first physician ask another on duty emergency physician to complete a second data collection form, without knowledge of the first physician's findings. The study nurse collected the data forms, verified data, confirmed eligibility, and performed telephone follow-up at one and six months when necessary. Study nurses also reviewed all records of emergency department visits to identify any missed eligible patients. If patients with headache were not clearly excluded by the eligibility criteria, they were deemed to be a missed eligible patient. For these patients we recorded information on age, sex, arrival by ambulance, computed tomography, lumbar puncture, and diagnosis of subarachnoid haemorrhage on a standardised missed patient data collection form. Review of health records and structured telephone follow-up were conducted as necessary to identify missed subarachnoid haemorrhage by using the same outcome criteria as used for enrolled patients.

\section{Outcome measures}

Subarachnoid haemorrhage was defined by subarachnoid blood on unenhanced computed tomography of the head, xanthochromia in the cerebrospinal fluid, or red blood cells $\left(>5 \times 10^{6} / \mathrm{l}\right)$ in the final sample of cerebrospinal fluid, with an aneurysm or arteriovenous malformation evident on cerebral angiography. This outcome was established a priori by consensus with five emergency physicians and one neurosurgeon. ${ }^{20}$

All results of computed tomography were verified by the local attending radiologists (either neuroradiologists or general radiologists who routinely interpret computed tomograms of the head). The radiologists were blinded to the contents of the data collection forms when they interpreted the scans but had the usual clinical information. Radiologists, as per usual practice at the time of the study, provided a final radiology report within one to three days after the scan. All computed tomographic scanners were third generation scanners. Lumbar puncture was done as per local practice, with the laboratory technicians visually inspecting the cerebrospinal fluid for the presence of red blood cells or xanthochromia. ${ }^{20-23}$

As the study protocol did not alter current practice, many patients were discharged without computed tomography and a lumbar puncture. We reviewed medical records of these patients (both enrolled and missed eligible patients) and carried out a structured telephone interview at one month and six months to identify any subsequent adverse events. At review or follow-up we assessed repeat visits to a physician, change in diagnosis, and subsequent testing with computed tomography, lumbar puncture, angiography, or magnetic resonance imaging. We internally validated our follow-up tool to identify subarachnoid haemorrhage. Patients who could not be contacted by telephone, despite at least five repeated attempts at varying times of the day, had an additional review of health records at the end of the study to see if they had any subsequent hospital encounters. At all five sites in Ontario, those patients lost to al follow-up were further checked against records from the provincial coroner's office to identify any deaths compatible with subarachnoid haemorrhage.

\section{Data analysis}

Univariate analyses determined the strength of the association between each of 26 possible predictor variables 
and the outcome variable. We used Pearson's $\chi^{2}$ or Fisher's exact test for nominal variables and the unpaired two tailed $t$ test for continuous variables, using either pooled or separate variance estimates as appropriate. We further explored variables of potential interest (either on statistical or clinical basis) using clinically sensible cut points. Cut points were used to ensure the final model did not contain any continuous variables so that clinicians could categorise patients as high or low risk without performing any calculations. The interobserver agreement for each variable was measured with the $k$ coefficient or Spearman's interclass coefficient, which measures the potential agreement beyond chance.

We then developed multivariate models to predict subarachnoid haemorrhage. Variables found to be associated at an $\alpha<0.20$ were evaluated with $\chi^{2}$ recursive partitioning analysis. This cut point was chosen to limit the number of associated variables, without requiring variables to be significant until we adjusted for the effect of confounding variables. Recursive partitioning was performed with KnowledgeSEEKER 6.0 software (Agnoss, Toronto, ON) to generate highly sensitive models. In addition to using variables with good interobserver reliability $(\kappa>0.6)$, we considered only models that made clinical sense and could be easily incorporated into clinical practice.

We chose recursive partitioning analysis over logistic regression analysis because our objective was to correctly classify one outcome group at the expense of the other (that is, high sensitivity is more important than overall accuracy). Recursive partitioning has been used to derive the Ottawa ankle rules, Ottawa knee rule, Canadian C-spine rule, and the Canadian CT head rule for minor trauma. ${ }^{24-27}$

\section{Sample size}

We estimated our sample size based on the objective of developing a clinical decision rule. We determined that a clinical decision rule for a life threatening problem such as subarachnoid haemorrhage would need $100 \%$ sensitivity with a narrow confidence interval (such as $97 \%$ to $100 \%$ ). Based on a cohort prevalence of $6.7 \%$ of subarachnoid haemorrhage in previous pilot study, we calculated that we required a total of 120 patients with subarachnoid haemorrhage, corresponding to a total sample size of 1800 enrolled patients.

\section{RESULTS}

We enrolled 1999 patients, 130 of whom had confirmed subarachnoid haemorrhage (fig 1). Of the remaining 1869 , only 26 were lost to active followup. None of these patients was seen at the regional neurosurgical referral centre within six months of their index visit. For five sites (accounting for 25 of the 26 patients), we were able to search provincial coroner reports (reporting is required by law for all sudden and unexpected deaths), and none of those lost to follow-up had died.

We identified $1050(34.4 \%)$ potentially eligible headache patients who were not enrolled. If we could not conclusively determine that they did not meet our eligibility criteria on review of the emergency department visit we deemed them as "missed eligible." The demographics were similar to enrolled patients (mean age $44.0 ; 59.9 \%$ women; $22.9 \%$ arrived by ambulance), though fewer were investigated $(73.0 \%$ underwent computed tomography, $36.7 \%$ underwent lumbar puncture) and fewer ultimately had a diagnosis of subarachnoid haemorrhage (2.7\%). At telephone followup at one and six months, we confirmed the absence of subsequent subarachnoid haemorrhage in all patients contacted $(87.5 \%$ at one month and $80.6 \%$ at six months). None of these patients had return visits to the regional neurosurgical referral centre within six months of their initial visit.

Table 1 lists the characteristics of our study cohort. Overall, patients were relatively young, more than half were women, and over three quarters described the headache as the worst of their lives. The time from onset was relatively fast, with a mean time from onset to peak of around nine minutes. About a third of patients complained of neck pain and another third reported vomiting. In all, 1657 (82.9\%) patients were investigated with computed tomography of the head, lumbar puncture, or both. Most (1521, 81.4\%) were diagnosed with benign headaches (such as tension, cluster, or other headache without a serious aetiology identified at the time of their six month follow-up) or migraine (according to the final diagnosis of the emergency physician). In addition to the cases of subarachnoid haemorrhage, computed tomography or lumbar puncture led to a diagnosis of other serious illnesses in 48 patients (such as transient ischaemic attack/acute ischaemic stroke, other types of haemorrhagic stroke, bacterial meningitis, hypertensive emergency, or cerebral neoplasm). All but nine cases of subarachnoid haemorrhage were identified by the radiologist's final interpretation of the computed tomogram. Of these nine patients with negative results on computed tomography, seven had xanthochromia and two had red blood cells in the cerebrospinal fluid with positive results on cerebral angiography. Emergency physicians initially misinterpreted the computed tomogram as normal in three cases and discharged the patients home. These three patients were recalled after radiologists reviewed the computed tomogram. In another case, the radiology resident initially misinterpreted the computed tomogram as normal but the patient went on to have a lumbar puncture that showed blood in the cerebrospinal fluid. This blood was thought to be

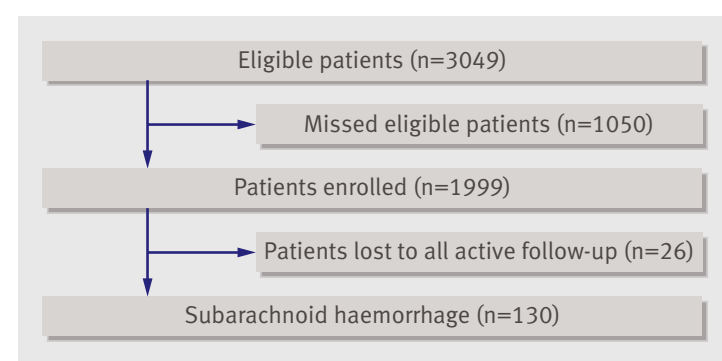

Fig 1| Details of enrolment and flow of patients in study 
Table 1/Characteristics of 1999 patients enrolled in study. Figures are numbers (percentages) unless stated otherwise

\begin{tabular}{|c|c|}
\hline Characteristics & No of patients \\
\hline Mean (SD) age (years) & $43.4(17.1)$ \\
\hline Age range (years) & 16-93 \\
\hline Female & $1207(60.4)$ \\
\hline Arrival by ambulance & $387(19.4)$ \\
\hline Transfer from another emergency department & $172(8.6)$ \\
\hline Mean (SD) duration of headache (hours) at time of assessment & $8.8(10.1)$ \\
\hline Mean (SD) time from onset to peak (minutes) & $8.8(17.5)$ \\
\hline Mean (SD) pain severity at peak (scale $0-10$ ) & $8.6(1.9)$ \\
\hline Onset during exertion & $228(11.5)$ \\
\hline Onset during sexual activity & $118(6.0)$ \\
\hline Headache awoke patient from sleep & $369(18.7)$ \\
\hline Worst headache of life & $1546(78.5)$ \\
\hline Loss of consciousness & $106(5.3)$ \\
\hline Witnessed loss of consciousness & $62(63.9)$ \\
\hline Complaint of neck stiffness or pain & $661(33.5)$ \\
\hline Vomiting & $558(28.4)$ \\
\hline Patient had neck stiffness with flexion and extension & $130(6.9)$ \\
\hline Mean (SD) heart rate (beats/min) & $80.1(15.4)$ \\
\hline Mean (SD) systolic blood pressure $(\mathrm{mm} \mathrm{Hg})$ & $142.6(24.9)$ \\
\hline Mean (SD) diastolic blood pressure $(\mathrm{mm} \mathrm{Hg})$ & $81.3(13.6)$ \\
\hline \multicolumn{2}{|l|}{ Diagnostic procedures and disposition } \\
\hline Computed tomography & $1606(80.3)$ \\
\hline Lumbar puncture & $905(45.3)$ \\
\hline Computed tomography or lumbar puncture & $1657(82.9)$ \\
\hline Both computed tomography and lumbar puncture & $854(42.7)$ \\
\hline Cerebral angiography* & $167(8.4)$ \\
\hline Admitted to hospital & $204(10.2)$ \\
\hline Died & $12(0.6)$ \\
\hline \multicolumn{2}{|l|}{ Final diagnosis } \\
\hline Benign headache & $1011(54.1)$ \\
\hline Migraine headache & $510(27.3)$ \\
\hline Subarachnoid haemorrhage & $130(6.5)$ \\
\hline Viral illness & $85(4.3)$ \\
\hline Ischaemic stroke or transient ischaemic attack & $34(1.8)$ \\
\hline Postcoital headache & $28(1.5)$ \\
\hline Sinusitis & $26(1.4)$ \\
\hline Vasovagal syncope & $23(1.2)$ \\
\hline Neck strain & $16(0.8)$ \\
\hline Brain tumour & $7(0.4)$ \\
\hline Hypoglycaemia & $4(0.2)$ \\
\hline Intracerebral haemorrhage & $4(0.2)$ \\
\hline Subdural haematoma & $2(0.1)$ \\
\hline Bacterial meningitis & $1(0.05)$ \\
\hline Other benign cause $\dagger$ & $117(5.6)$ \\
\hline
\end{tabular}

secondary to traumatic tap $\left(632000 \times 10^{6} / \mathrm{l}\right.$ in the fourth tube) and the neurosurgery resident discharged the patient home with follow-up magnetic resonance angiography booked in five days. This angiogram showed an aneurysm, which was managed surgically. No other cases of subarachnoid haemorrhage were missed on the initial emergency department visit.
Many of the variables cited in the literature on subarachnoid haemorrhage were associated with the condition in our patients (table 2). For the 103 patients who had two independent physician assessments, there was substantial interobserver agreement for being awoken by headache, transient loss of consciousness, vomiting, complaint of neck stiffness or pain, and onset with exertion. Interobserver agreement was poor for the worst headache of life and needing to rest. The interclass correlation coefficient calculated for the continuous variables showed poor correlation for time from onset to peak of headache and substantial agreement for peak pain intensity (on a scale from 0 to 10 , where $0=$ no pain and $10=$ worst pain ever).

Figure 2 shows an example of $\chi^{2}$ recursive partitioning for rule 1 . This same method was used to derive rules 2 and 3 . This figure shows the sequential stepwise analysis in which the most predictive variable is chosen at each level, until a low risk group without any cases of subarachnoid haemorrhage remains. Patients with any one of the variables who had subarachnoid haemorrhage form the high risk group.

Each model suggests that only patients with any of the high risk variables will need to be investigated. The box displays the three derived rules, and table 3 shows their respective classification of performance. All three rules have retrospective sensitivity of $100 \%$ (95\% confidence interval $97.1 \%$ to $100.0 \%$ ). The specificity of the models ranges from $28.4 \%$ to $38.8 \%$, with corresponding investigation rates (computed tomography, lumbar puncture, or both) from $63.7 \%$ to $73.5 \%$. Each of the three rules suggests a lower investigation rate than the current rate of $82.9 \%$. We conducted a post hoc bootstrapping analysis of 1000 iterations to determine the internal stability of each of the three models and found that the specificity was stable at each of the point estimates for each model with perfect sensitivity (see appendix 1 on bmj.com).

Variables included in each of three proposed rules For each rule, patients should be investigated if one or more of the variables are present

Rule 1

- Age $>40$

- Complaint of neck pain or stiffness

- Witnessed loss of consciousness

- Onset with exertion

Rule 2

- Arrival by ambulance

- Age $>45$

- Vomiting at least once

- Diastolic blood pressure $>100$ mm Hg

Rule 3

- Arrival by ambulance

- Systolic blood pressure $>160 \mathrm{~mm} \mathrm{Hg}$

- Complaint of neck pain or stiffness

- Age 45-55 
Table 2 | Interobserver agreement and univariate correlation of variables for subarachnoid haemorrhage. Figures are percentages (numbers) unless stated otherwise

\begin{tabular}{|c|c|c|c|c|}
\hline & \multicolumn{2}{|c|}{$\begin{array}{l}\text { Subarachnoid } \\
\text { haemorrhage }\end{array}$} & \multirow[b]{2}{*}{$P$ value } & \multirow[b]{2}{*}{$K(n=103)$} \\
\hline & No $(n=1869)$ & Yes $(n=130)$ & & \\
\hline \multicolumn{5}{|l|}{ Questions from history } \\
\hline Mean age (years) & 42.6 & 54.4 & $<0.001$ & NA \\
\hline Female & $60.6(1133)$ & $56.9(74)$ & 0.41 & NA \\
\hline Mean time from onset to peak (minutes) & 9.2 & 3.4 & $<0.002$ & $0.47^{\star}$ \\
\hline Mean pain severity at peak $(0-10)$ & 8.6 & 9.3 & $<0.001$ & $0.70^{\star}$ \\
\hline Onset during exertion & $10.7(200)$ & $23.1(30)$ & $<0.001$ & 0.61 \\
\hline Onset during sexual activity & $6.0(112)$ & $5.5(7)$ & 0.79 & 0.85 \\
\hline Headache awoke patient from sleep & $19.3(361)$ & $10.8(14)$ & 0.016 & 0.93 \\
\hline Worst headache of life & $77.5(1448)$ & $93.1(121)$ & $<0.001$ & 0.45 \\
\hline Loss of consciousness & $4.5(84)$ & $16.9(22)$ & $<0.001$ & 0.88 \\
\hline Witnessed loss of consciousness & $2.5(47)$ & $11.5(15)$ & $<0.001$ & 1.0 \\
\hline Needed to rest & $24.0(449)$ & $43.9(57)$ & $<0.001$ & 0.26 \\
\hline Complaint of neck stiffness or pain & 30.9 (578) & $71.1(92)$ & $<0.001$ & 0.65 \\
\hline Vomiting & $26.3(492)$ & $58.6(76)$ & $<0.001$ & 0.80 \\
\hline Ambulance & $16.7(312)$ & $56.9(74)$ & $<0.001$ & NA \\
\hline Emergency department transfer & 7.9 (148) & $18.5(24)$ & $<0.001$ & NA \\
\hline \multicolumn{5}{|l|}{ Questions from physical examination } \\
\hline Neck stiffness (flexion/extension) & $5.2(97)$ & $30.4(40)$ & $<0.001$ & 0.24 \\
\hline Mean (SD) temperature $\left({ }^{\circ} \mathrm{C}\right)$ & $36.4(1.9)$ & $36.3(1.5)$ & 0.39 & NA \\
\hline Mean (SD) heart rate (beats/min) & $80.2(15.5)$ & $79.0(13.9)$ & 0.38 & NA \\
\hline Mean (SD) systolic blood pressure $(\mathrm{mm} \mathrm{Hg})$ & $141(24.1)$ & $159(29.3)$ & $<0.001$ & NA \\
\hline Mean (SD) diastolic blood pressure $(\mathrm{mm} \mathrm{Hg})$ & $81(13.4)$ & 88 (13.9) & $<0.001$ & NA \\
\hline
\end{tabular}

$\mathrm{NA}=$ not applicable.

*Spearman's interclass correlation coefficient.

\section{DISCUSSION}

In a five year multicentre study we derived three decision rules using clinical findings to identify which neurologically intact patients with headache require investigation to rule out arguably the most serious cause of headache, subarachnoid haemorrhage. Arrival by ambulance, age $\geq 40$, complaint of neck stiffness or pain, onset with exertion, vomiting, witnessed loss of consciousness, and raised blood pressure were strongly and reliably associated with subarachnoid haemorrhage. The presence of one or more of these findings in a patient with an acute non-traumatic headache reaching maximum intensity within one hour and that is unlike previous headaches should prompt physicians to consider investigating for subarachnoid haemorrhage.

We have previously shown that while physicians can discriminate between patients with subarachnoid haemorrhage and other forms of headache, they are reluctant to do so solely on their clinical findings. ${ }^{28}$ Our clinical decision rules, if validated, should provide physicians with evidence to manage more headache patients safely without investigation. Beyond healthcare costs, investigations entail exposure to radiation and perhaps intravenous contrast medium, difficulties in interpreting erythrocyte counts in traumatic lumbar punctures with false positive results, the indirect costs of incidental findings, and the morbidity of a headache after dural puncture. More selective testing can also shorten length of stay in an overcrowded emergency department. We have previously shown that computed tomography of the head adds about three hours to a patient's length of stay, and performing a lumbar puncture adds another four hours. ${ }^{3}$

We are not aware of previous studies on clinical decision rules in patients with headache and normal results on neurological examinations. One small prospective study in 137 headache patients, including 23 cases of subarachnoid haemorrhage, concluded, without conducting a multivariate analysis, that there was no single clinical feature that could reliably identify which patients with headache require investigation. ${ }^{29}$ Other previous studies have attempted to identify risk factors and features suggestive of subarachnoid haemorrhage. A retrospective study of 500 patients with aneurysmal subarachnoid haemorrhage found that risk factors included women aged over 50, men aged under 50, and stressful events. ${ }^{30}$ Other proposed risk factors include alcohol consumption, smoking, hypertension, and oral contraceptives, but these variables are prevalent among many patients in emergency departments and might not be clinically useful for differentiating subarachnoid haemorrhage from other headaches. ${ }^{31-45}$ Uncommon connective tissue disorders, including Ehlers-Danlos syndrome type IV, autosomal dominant polycystic kidney disease, and Marfan's syndrome, can lead to subarachnoid haemorrhage but are absent in most patients with subarachnoid haemorrhage. ${ }^{1446-51}$ Neck stiffness is often cited in reviews of the topic. ${ }^{1214}$ Other associations with subarachnoid haemorrhage include acutely raised blood pressure. ${ }^{12}$

\section{Strengths of study}

To develop the clinical decision rules, we followed previously established methodological standards for developing and testing. ${ }^{52-55}$ We clearly defined our outcome, subarachnoid haemorrhage, and it was assessed

Age $\mathbf{4} \mathbf{4 0}$ ?

(1999 patients, 130 had subarachnoid haemorrhage)

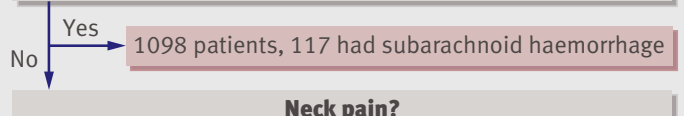

(901 patients, 13 had subarachnoid haemorrhage)

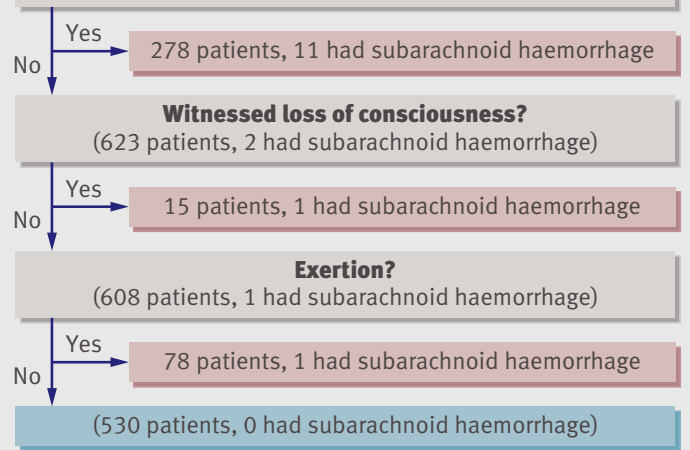

Low risk: no investigation required High risk: require investigation

Fig 2 Example of recursive partitioning analysis with rule 1: age $\geq 40$, complaint of neck pain or stiffness, witnessed loss of consciousness, onset of pain during exertion 
without knowledge of the predictor variables. The predictor variables were prospectively evaluated and documented on standardised data collection forms before head computed tomography or lumbar puncture. We assessed the interobserver reliability of the predictor variables by having an independent second physician repeat the assessment of the patient. Patients were selected without bias and did not differ significantly from missed eligible patients. We were estimating the classification of performances of the clinical decision rules. The large sample size allowed us to achieve narrow confidence intervals for sensitivity. Each of our derived rules contains only four variables, all of which are relatively simple and well defined, which should allow clinicians to easily incorporate the optimal rule into everyday practice.

We set out to derive one or more models that met the methodological standards for development of a clinical decision rule. In particular we sought models that had strong statistical association with subarachnoid haemorrhage and that were clinically sensible and easy to use. We opted to retain the three best performing models for further evaluation, partly because of the high morbidity or mortality associated with a missed diagnosis. In addition, we had some reservation regarding arrival by ambulance as a component of any rule. While this strong predictor presumably captures a measure of severity of headache and seriousness perceived by the patient, it is also probably strongly influenced by the local pre-hospital system and might not be transferrable to regions where people have differing thresholds for calling for an ambulance. Hence, we opted to keep one model without the ambulance variable for additional study.

While we identified a few cases of misdiagnosed subarachnoid haemorrhage, most tests performed yielded negative results. Given the increased costs of medical care and increasing problems of overcrowding in emergency departments, improved diagnostic efficiency is particularly important. Use of these rules could eliminate the need for any tests without missing any cases of subarachnoid haemorrhage for between one in five and one in 10 patients presenting to the emergency department with a headache peaking within an hour.

Forty eight enrolled patients had serious conditions other than subarachnoid haemorrhage. For these patients, it was apparent from the documentation that physicians were concerned about the possibility of other pathology before they obtained results of imaging or lumbar puncture. We did not explicitly ask physicians if they were investigating for other conditions on the study forms or exclude patients in whom subarachnoid haemorrhage was not the most probable serious diagnostic consideration. Given the heterogeneity of headache, it would be impractical to generate one clinical decision rule for all causes. Generally speaking, most other causes of serious headache would have other clinical clues (such as fever and transient or persistent neurological deficits) to help guide investigations for other significant pathology.

\section{Limitations}

Our inclusion criteria allowed for patients with nonthunderclap headaches to be enrolled by specifying an onset to peak intensity of up to one hour. While this could have diluted the acuity, we note that the reported time to peak headache intensity was up to several minutes in our patients with subarachnoid haemorrhage. In addition, we excluded patients with a history of three or more similar headaches (same intensity and character) in the past over a time frame of over six months. This was intended to eliminate patients with chronic recurrent headaches, in whom our rules should not be applied. We recognise that physicians might overlook exclusion criteria when applying any decision rule and emphasise that such extrapolation is not evidence based. Another potential limitation was the lack of an established standard definition of a positive subarachnoid haemorrhage. We believe that our composite outcome is the best definition available at this time. In addition, we derived three potential clinical decision rules rather than choosing just the best performing rule, mainly on the basis that arrival by ambulance might not be useful without validation in

Table 3 |Classification of performance of rules to identify patients who require further investigation for subarachnoid haemorrhage

\begin{tabular}{|c|c|c|c|c|c|c|}
\hline & \multicolumn{2}{|c|}{$\begin{array}{l}\text { Subarachnoid } \\
\text { haemorrhage }\end{array}$} & \multirow[b]{2}{*}{ Sensitivity $(95 \% \mathrm{Cl})$} & \multirow[b]{2}{*}{ Specificity $(95 \% \mathrm{Cl})$} & \multirow[b]{2}{*}{ Negative predictive value } & \multirow[b]{2}{*}{ Investigation rate } \\
\hline & Yes & No & & & & \\
\hline \multicolumn{7}{|l|}{ Rule 1* } \\
\hline High risk & 130 & 1339 & $100 \%$ & $28.4 \%$ & $100 \%$ & \multirow{2}{*}{$73.5 \%$} \\
\hline Low risk & 0 & 530 & (97.1\% to $100.0 \%)$ & (26.4\% to $30.4 \%$ ) & (99\% to $100 \%)$ & \\
\hline \multicolumn{7}{|l|}{ Rule $2 \dagger$} \\
\hline High risk & 130 & 1186 & $100 \%$ & $36.5 \%$ & $100 \%$ & \multirow{2}{*}{$65.8 \%$} \\
\hline Low risk & 0 & 683 & (97.1\% to $100.0 \%)$ & (34.4\% to $38.8 \%$ ) & (99\% to $100 \%)$ & \\
\hline \multicolumn{7}{|l|}{ Rule $3 \ddagger$} \\
\hline High risk & 130 & 1143 & $100 \%$ & $38.8 \%$ & $100 \%$ & \multirow{2}{*}{$63.7 \%$} \\
\hline Low risk & 0 & 726 & (97.1\% to $100.0 \%)$ & (36.7\% to $41.1 \%$ ) & (99\% to $100 \%)$ & \\
\hline
\end{tabular}

*Age $\geq 40$, complaint of neck stiffness or pain, witnessed loss of consciousness, onset of pain during exertion.

$\dagger$ Arrival by ambulance, age $\geq 45$, vomiting, diastolic blood pressure $\geq 100 \mathrm{~mm} \mathrm{Hg}$.

łArrival by ambulance, systolic blood pressure $\geq 160 \mathrm{~mm} \mathrm{Hg}$, complaint of neck stiffness or pain, age 45-55. 


\section{WHAT IS ALREADY KNOWN ON THIS TOPIC}

Subarachnoid haemorrhage can occur in emergency patients presenting with sudden severe headache, even if they are neurologically intact at initial presentation

Lumbar puncture is traditionally carried out to exclude this possibility, even if results of computed tomography are negative

Most sudden headaches are benign and self limiting; universal investigation is inefficient and involves unnecessary exposure to radiation and post-lumbar puncture headache

\section{WHAT THIS STUDY ADDS}

Three similar but distinct decision rules for subarachnoid haemorrhage have perfect sensitivity and are based on readily available pragmatic and consistent predictor variables

Use of any one of these rules can reduce unnecessary investigation without missing any cases of subarachnoid haemorrhage

regions with different cultural or business models for ambulance services.

As many as a third of eligible patients might not have been enrolled in this study. This is almost certainly overstating the magnitude of this potential limitation as we coded patients as being "missed" if we could not definitely determine that they did not meet the eligibility criteria. Because of poor recording, often we could not determine how rapidly the headache peaked. Hence, by default, these patients were deemed missed, even though many would probably not have peaked within one hour. This conclusion is reinforced by the lower investigation rates and lower rates of subarachnoid haemorrhage in these "missed" patients.

Finally, the proposed clinical rules need to be validated before being incorporated fully in clinical practice, as essential component of the development of any clinical decision rule. While we did carry out bootstrapping analysis for internal validation, the rules require independent validation before they can be implemented.

\section{Clinical implications}

While the rules should not yet be used to explicitly rule out subarachnoid haemorrhage, they certainly can be considered to help to identify high risk patients. Hence, patients with any one or more of the seven findings (age $\geq 40$, witnessed loss of consciousness, complaint of neck pain or stiffness, onset with exertion, arrival by ambulance, vomiting, diastolic blood $\geq 100 \mathrm{~mm} \mathrm{Hg}$ or systolic blood $\geq 160 \mathrm{~mm} \mathrm{Hg}$ ) should be considered carefully for subarachnoid haemorrhage and undergo rapid and thorough investigation to rule out this life threatening condition.

\section{Research implications}

The three proposed rules are being prospectively and explicitly evaluated in an ongoing study to determine their accuracy for subarachnoid haemorrhage, their interobserver agreement for interpretation, and their potential impact on investigation. Once this prospective evaluation has been completed, the optimal rule can be chosen for implementation into clinical practice. The best performing rule will allow clinicians to be more selective in determining which patients require investigation. This will improve care of patients by directing testing for those at high risk who might otherwise not be adequately investigated. At the same time, the rule should result in no computed tomography or lumbar puncture for patients at low risk, thus decreasing their morbidity from unnecessary tests.

We thank the hundreds of physicians who completed our data collection forms and all the emergency department nurses and clerks at the six study sites for their cooperation. We thank Albert E Lauwers, deputy coroner, and the Office of the Coroner of Ontario assistance with verifying outcomes. We also thank Evelyn Gilkinson (London Health Sciences Centre, London, Ontario); Erica Battram and Nicole Fortin (Ottawa Hospital, Civic Campus and General Campus, Ottawa, Ontario); Harris Lari, Leslie Saunders, Ginny Willis, and Sandy Sandilands (University of Alberta Health Sciences Centre, Edmonton, Alberta); Deborah Wright and Johanna Pak (Sunnybrook and Women's College Health Sciences Centre, Toronto, Ontario); Kathy Bowes, Julie Richard, Deborah Crosby, and Jane Reid (Kingston General Hospital, Kingston, Ontario); and our colleagues at the Ottawa Hospital Research Institute (My-Linh Tran, Irene Harris, and Angela Marcantonio) for their assistance with this project. Contributors: JPP developed and contributed substantially to study concept and design and secured research funding. JIP IGS, MLAS, MIB, JSL, ME, HL, and GAW participated in the study design and supervised in the recruitment of patients and management of data. All authors supervised in the conduct of the trial and data collection, drafted the manuscript and/or contributed to its revision, and approved the final version. JJP, IGS, and GAW provided statistical advice and data analysis, JJP is guarantor.

Funding: This study was funded by Ontario Ministry of Health and Long Term Care, physicians of Ontario through the Physician's Services Incorporated Foundation (grant No 01-39), the Canadian Institutes for Health Research (grant No 67107). JJP was funded as a career scientist by the Ontario Ministry of Health and is now funded by a Canadian Institutes for Health Research New Investigator Award. IGS is a University Health Research Chair, University of Ottawa.

Competing interests: All authors have completed the Unified Competing Interest form at www.icmje.org/coi_disclosure.pdf (available on request from the corresponding author) and declare: no support from any institution for the submitted work; no financial relationships with any institutions that might have an interest in the submitted work in the previous 3 years; no other relationships or activities that could appear to have influenced the submitted work

Ethical approval: The study protocol was approved by the research ethics boards at each centre without the need for written informed consent as patients continued to be investigated as per current practice. Participants were informed that they could be contacted by telephone for an update on their status, and verbal consent was obtained at the time of the telephone call.

Data sharing: No additional data available.

1 Edlow IA, Panagos PD, Godwin SA, Thomas TL, Decker WW. Clinical policy: critical issues in the evaluation and management of adult patients presenting to the emergency department with acute headache. Ann Emerg Med 2008;52:407-36.

2 Vermeulen M, van Gijn J. The diagnosis of subarachnoid haemorrhage. J Neurol Neurosurg Psychiatry 1990;53:365-72.

3 Perry JJ, Stiell IG, Wells GA, Spacek AM. Historical cohort study. Use and yield of investigations for alert patients with possible subarachnoid hemorrhage. Can J Emerg Med 2002;4:333-7.

4 Morgenstern LB, Huber IC, Luna-Gonzales H, Saldin KR, Grotta JC, Shaw SG, et al. Headache in the emergency department. Headache 2001;41:537-41.

5 Van Gijn J, Kerr RS, Rinkel GJ. Subarachnoid haemorrhage. Lancet 2007;369:306-18.

6 Weir B. Headaches from aneurysms. Cephalalgia 1994;14:79-87

7 Schievink W, van der Werf D, Hageman L, Dreissen J. Referral pattern of patients with aneurysmal subarachnoid hemorrhage. Surg Neurol 1988;29:367-71.

8 Schull M, Vermeulen M. Missed diagnosis of subarachnoid hemorrhage in the emergency department: a population-based analysis. Acad Emerg Med 2004;11:487.

9 Kowalski RG, Claassen J, Kreiter KT, Bates JE, Ostapkovich ND, Connolly ES, et al. Initial misdiagnosis and outcome after subarachnoid hemorrhage. JAMA 2004;291:866-9. 
10 Vermeulen MJ, Schull MJ. Missed diagnosis of subarachnoid hemorrhage in the emergency department. Stroke 2007;38:1216-21.

11 Brisman JL, Song JK, Newell DW. Cerebral aneurysms. N Engl J Med 2006;355:928-39.

12 Edlow JA, Caplan LR. Avoiding pitfalls in the diagnosis of subarachnoid hemorrhage. N Engl J Med 2000;342:29-36.

13 Suarez II, Tarr RW, Selman WR. Aneurysmal subarachnoid hemorrhage. N Engl J Med 2006;354:387-96.

14 Schievink WI. Intracranial aneurysms. N Engl J Med 1997;336:28-40.

15 Hillman J, Saveland H, Jakobsson K-E, Edner G, Zygmunt S, Fridriksson S, et al. Overall management outcome of ruptured posterior fossa aneurysms. J Neurosurg 1996;85:33-8.

16 Leicht MJ. Non-traumatic headache in the emergency department. Ann Emerg Med 1980;9:404-9.

17 Bonita R, Thomson S. Subarachnoid hemorrhage: epidemiology, diagnosis, management, and outcome. Stroke 1985;16:591-4.

18 Berrington de Gonzalez A, Darby S. Risk of cancer from diagnostic Xrays: estimates for the UK and 14 other countries. Lancet 2004;363:345-51

19 Evans RW, Armon C, Frohman EM, Goodin DS. Assessment: prevention of post-lumbar puncture headaches. Neurology 2000;55:909-14.

20 Tsementzis SA, Hitchcock ER, DeCothi A, Gill JS. Comparative studies of the diagnostic value of cerebrospinal fluid spectrophotometry and computed tomographic scanning in subarachnoid hemorrhage. Neurosurgery 1985;17:908-12.

21 Sames T, Storrow A, Finkelstein J, Magoon M. Sensitivity of newgeneration computed tomography in subarachnoid hemorrhage. Acad Emerg Med 1996;3:16-20.

22 Perry JJ, Sivilotti MLA, Stiell IG, Wells GA, Raymond J, Mortensen M, et al. Should spectrophotometry be used to identify xanthochromia in the cerebrospinal fluid of alert patients suspected of having subarachnoid hemorrhage? Stroke 2006;37:2472.

23 Van der Wee N, Rinkel GJE, Hasan D, van Gijn J. Detection of subarachnoid haemorrhage on early CT: is lumbar puncture stil needed after a negative scan? J Neurol Neurosurg Psychiatry 1995; 58:357-9.

24 Stiell IG, Wells GA, Vandemheen K, Clement C, Lesiuk H, De Maio V], et al. The Canadian cervical spine radiography rule for alert and stable trauma patients. JAMA 2001;286:1841-8.

25 Stiell IG, Greenberg GH, Wells GA, McKnight RD, Cwinn AA, Cacciotti T, et al. Derivation of a decision rule for the use of radiography in acute knee injuries. Ann Emerg Med 1995;26:405-13.

26 Stiell IG, Wells GA, Vandemheen K, Clement C, Lesiuk H, Laupacis A et al. The Canadian CT head rule for patients with minor head injury. Lancet 2001;357:1391-6.

27 Stiell IG, Greenberg GH, McKnight RD, Nair RC, McDowell I, Worthington JR. A study to develop a clinical decision rule for the use of radiography in acute ankle injuries. Ann Emerg Med 1992;21:384-90.

28 Perry JJ, Stiell IG, Wells GA, Mortensen M, Lesiuk H, Sivilotti M, et al. Attitudes and judgement of emergency physicians in the management of patients with acute headache. Acad Emerg Med 2005;12:33-7.

29 Landtblom A-M, Fridriksson S, Boivie J, Hillman J, Johansson G, Johansson I. Sudden onset headache: a prospective study of features, incidence and causes. Cephalalgia 2002;22:354-60.

30 Schievink WI, Karemaker JM, Hageman LM, van der Werf DJM. Circumstances surrounding aneurysmal subarachnoid hemorrhage. Surg Neurol 1989;32:266-72.

31 Longstreth WT, Nelson LM, Koepsell TD, van Belle G. Subarachnoid hemorrhage and hormonal factors in women-a population-based case-control study. Ann Intern Med 1994;121:168-73.

32 Feigin VL, Rinkel GJ, Lawes CM, Algra A, Bennett DA, van Gijn J, et al. Risk factors for subarachnoid hemorrhage: an updated systematic review of epidemiological studies. Stroke 2005;36:2773-80.

33 Taylor CL, Yuan Z, Selman WR, Ratcheson RA, Rimm AA. Cerebral arterial aneurysm formation and rupture in 20,767 elderly patients: hypertension and other risk factors. J Neurosurg 1995;83:812-9.
34 Bassi P, Bandera R, Loiero M, Tognoni G, Mangoni A. Warning signs in subarachnoid hemorrhage: a cooperative study. Acta Neurol Scand 1991;84:277-81.

35 Adamson J, Humphries SE, Ostergaard JR, Voldby B, Richards P, Powell JT. Are cerebral aneurysms atherosclerotic? Stroke 1994;25:963-6.

36 Adams HP, Jergenson DD, Kassell NF, Sahs AL. Pitfalls in the recognition of subarachnoid hemorrhage. JAMA 1980;244:794-6

37 Neil-Dwyer G, Lang DT. "Brain attack"-aneurysmal subarachnoid haemorrhage: death due to delayed diagnosis. J R Coll Physicians Lond 1997;31:49-52.

38 Sakas DE, Dias LS, Beale D. Subarachnoid haemorrhage presenting as head injury. BMJ 1995;310:1186-7.

39 Ramirez-Lassepas M, Espinosa CE, Cicero JJ, Johnston KL, Cipolle RJ, Barber DL. Predictors of intracranial pathologic findings in patients who seek emergency care because of headache. Arch Neurol 1997;54:1506-9.

40 Roost KT, Pimstone NR, Diamond I, Schmid R. The formation of cerebrospinal fluid xanthochromia after subarachnoid hemorrhage. Neurology 1972;22:973-7.

41 Juvela S, Hillbom M, Numminen H, Koskinen P. Cigarette smoking and alcohol consumption as risk factors for aneurysmal subarachnoid hemorrhage. Stroke 1993;24:639-46.

42 Bonita R. Cigarette smoking, hypertension and the risk of subarachnoid hemorrhage: a population-based case-control study. Stroke 1986;17:831-4.

43 Petitti DB, Sidney S, Bernstein A, Wolf S, Quesenberry C, Ziel HK. Stroke in users of low-dose oral contraceptives. N Engl J Med 1996;335:8-15.

44 Toftdahl DB, Torp-Pedersen C, Engel UH, Strandgaard S, Jespersen B. Hypertension and left ventricular hypertrophy in patients with spontaneous subarachnoid hemorrhage. Neurosurgery 1995;37:235-40.

45 Vessey MP, Villard-Mackintosh L, McPherson K, Yeates D. Mortality among oral contraceptive users: 20 year follow up of women in a cohort study. BMJ 1989;299:1487-91.

46 Schievink WI, Prakash UBS, Piepgras DG, Mokri B. Alpha-1antitrypsin deficiency in intracranial aneurysms and cervical artery dissection. Lancet 1994;343:452-3.

47 Schievink WI, Katzmann JA, Piepgras DG, Schaid DJ. Alpha-1 antitrypsin phenotypes among patients with intracranial aneurysms. I Neurosurg 1996;84:781-4.

48 Schievink WI, Michels W, Piepgras DG. Neurovascular manifestations of heritable connective tissue disorders: a review. Stroke 1994;25:889-903.

49 Butler WE, Barker FG, Crowell RM. Patients with polycystic kidney disease would benefit from routine magnetic resonance angiographic screening for intracerebral aneurysms: a decision analysis. Neurosurgery 1996;38:506-16.

50 Chapman AB, Rubinstein D, Hughes R, Stears JC, Earnest MP, Johnson AM, et al. Intracranial aneurysms in autosomal dominant polycystic kidney disease. N Engl J Med 1992;327:916-20.

51 Wiebers DO, Torres VE. Screening for unruptured intracranial aneurysms in autosomal dominant polycystic kidney disease. N Engl Med 1992;327:953-5.

52 Stiell IG, Wells GA. Methodologic standards for the development of clinical decision rules in emergency medicine. Ann Emerg Med 1999;33:437-47.

53 McGinn TG, Guyatt GH, Wyer PC, Naylor CD, Stiell IG, Richardson WS Users' guides to the medical literature: XXII: How to use articles about clinical decision rules. JAMA 2000;284:79-84.

54 Wasson JH, Sox HC, Neff RK, Goldman L. Clinical prediction rules: applications and methodological standards. N Engl J Med 1985;313:793-9.

55 Laupacis A, Sekar N, Stiell IG. Clinical prediction rules: a review and suggested modifications of methodological standards. JAMA 1997;277:488-94.

Accepted: 31 August 2010 